\title{
Fruit and vegetable intake and its correlates among high-school adolescents in Iran: a cross-sectional study
}

\author{
Reza Ziaei ${ }^{1}$ (1) Hadi Shahi $^{2} \cdot$ Saeed Dastgiri ${ }^{3} \cdot$ Reza Mohammadi $^{4} \cdot$ Eija Viitasara $^{5}$
}

Received: 4 March 2019 / Accepted: 7 May 2019 / Published online: 21 May 2019

(C) The Author(s) 2019

\begin{abstract}
Background Two important components of a healthy diet are fruits and vegetables $(\mathrm{F} \& \mathrm{~V})$, which are essential for maintaining physical health. The aim of the present study was to assess the prevalence and correlates of $F \& V$ intake among high school adolescents in the city of Tabriz.

Methods The Global School-based Student Health Survey self-administered questionnaire was used for data collection among 1517 adolescents.

Results The prevalence of fruit intake was $76.1 \%$ ( $\geq 2$ times/day) and vegetable intake $23 \%$ ( $\geq 3$ times/day). Being at the third level of high school and having sedentary behavior, low intake of vegetables, low or lack of parental support, lack of peer support and lack of enough food at home were significantly associated with low consumption of fruit among students. Also, being overweight or obese and having low intake of fruit, low or lack of peer support, and being physically inactive were significantly associated with low intake of vegetables.

Conclusion Results suggest that interventions targeting personal, interpersonal and environmental factors for increased $\mathrm{F} \& \mathrm{~V}$ consumption should be given more priority by the public health authorities.
\end{abstract}

Keywords Fruit intake $\cdot$ Vegetable intake $\cdot$ Physical activity $\cdot$ Students $\cdot$ Global school-based student health survey $\cdot$ Iran

\section{Introduction}

In 2005, according to the World Health Organization (WHO), 35 million deaths were due to non-communicable diseases (NCDs). Of these, $80 \%$ occurred in low- and middle-income countries (WHO 2018). For instance, in the Eastern Mediterranean Region (EMRO), NCDs are the leading cause of death, claiming 1.7 million lives annually (UN Secretary-General Report 2011). According to the World Health Organization (WHO), NCDs including cardiovascular disease (CVD), diabetes, obesity, certain types of cancer and chronic respiratory diseases will be

Reza Ziaei

Reza.Ziaei@miun.se

Hadi Shahi

Shahi.hadi@gmail.com

Saeed Dastgiri

Saeed.dastgiri@gmail.com

Reza Mohammadi

Reza.Mohammadi@ki.se

Eija Viitasara

Eija.viitasara@miun.se responsible for the deaths of 52 million people globally by 2030 (UN Secretary-General Report 2011).

The two important risk factors for NCDs are unbalanced diet and physical inactivity, and many scientific studies have shown that sufficient physical activity and a healthy diet play an important role in the prevention of NCDs (WHO 2018).

Two important components of a healthy diet are fruit and vegetables $(\mathrm{F} \& \mathrm{~V})$, which are essential for maintaining physical health. Adequate daily intake of $F \& V$ can promote health and prevent chronic conditions such as cardiovascular disease (CVD) (Key et al. 2002).

1 Department of Health Sciences, Unit for Public Health Science, Mid Sweden University, Sundsvall, Sweden

2 Tabriz Pediatrics Hospital, Unit of Nutrition and Diet Therapy, Tabriz University of Medical Sciences, Tabriz, Iran

3 Department of Community Medicine, Tabriz University of Medical Sciences, Tabriz, Iran

4 Department of Neurobiology, Care Sciences and Society, Unit for Family Medicine, Karolinska Institute, Stockholm, Sweden

5 Department of Health Sciences, Unit for Public Health Science, Mid Sweden University, Sundsvall, Sweden 
WHO and the Food and Agriculture Organization (FAO) recommend a daily intake of a minimum $400 \mathrm{~g}$ of fruit and vegetables (excluding potatoes and other starchy tubers), an equivalent of $\geq 2$ servings of fruit and $\geq 3$ servings of vegetables, to prevent chronic diseases (WHO 2003). According to the Center for Disease Control and Prevention (CDC) and WHO, insufficient fruit consumption is defined as eating fruit less than twice a day and inadequate vegetable consumption as less than three times a day (State Indicator Report on Fruits and Vegetables 2013; Agudo 2004; Adults Meeting Fruit and Vegetable Intake Recommendations 2013). Maintaining the recommended daily consumption of $\mathrm{F} \& \mathrm{~V}$ can reduce daily calorie intake for maintaining healthy body weight and managing related problems such as obesity and weight loss for adolescents (Nystrom et al. 2005).

Adolescence is a critical period in life and has an important role in the formation of behavioral and nutritional habits. Some studies have shown that behavioral risk factors associated with chronic disease, such as lack of exercise and unhealthy dietary habits, persist from adolescence into adulthood and tend to remain throughout life (Veltsista et al. 2010), while adolescence is the best time to adopt healthy lifestyle habits (Paudel et al. 2014).

In the majority of western countries, despite the importance of adequate intake of $\mathrm{F} \& \mathrm{~V}$, most adolescents consume far less than the recommended daily levels of F\&V (Vereecken et al. 2004; Yngve et al. 2005). In the USA, the data have shown that, among adolescents, the daily intake of F\&V has decreased (Larson et al. 2007), and a recent study showed that fewer than one in ten Americans meet the fruit and vegetable recommendations (Kimmons et al. 2009). Among Chinese students, only $14 \%$ of adolescents reached the daily recommended intake of $F \& V$ (Zhang et al. 2012). In Ghana, 56\% of adolescents rarely ate fruit and $48 \%$ rarely ate vegetables (Doku et al. 2013). The data from the Global School-based Student Health Survey (GSHS), carried out among school adolescents in seven African countries, showed that $77.5 \%$ of adolescents did not meet the WHO daily recommended intake of F\&V (Peltzer and Pengpid 2010). The data from the Pro-Green survey project among ten European countries revealed that the mean intake of $\mathrm{F} \& \mathrm{~V}$ among adolescents did not reach the WHO recommendation of $400 \mathrm{~g} /$ day (Lynch et al. 2014).

In Iran, according to a national survey (Caspian study) on adolescents' dietary behaviors, the intake of unhealthy food choices, such as salty, fatty and junk food snacks, was high. In contrast, the intake of $\mathrm{F} \& \mathrm{~V}$ was lower than the amount recommended (Kelishadi et al. 2007) by the United States Department of Agriculture (USDA) (Health Gov 2018) and WHO (WHO 2003). A recent study that evaluated F\&V intake among adolescents in Iran found that only $30.3 \%$ and $34.6 \%$ had the optimal consumption of fruit and vegetables, respectively (Shokrvash et al. 2013).

In designing effective interventions to increase $F \& V$ intake among adolescents, it is necessary to identify the correlates of $F \& V$ consumption. Some factors that were found significant in previous studies in relation to $F \& V$ intake among adolescents were socioeconomic status, age, gender, F\&V availability and accessibility at home, family and peer support, family encouragement and physical inactivity (Rasmussen et al. 2006; Pearson et al. 2009). In some other studies, inadequate $\mathrm{F} \& \mathrm{~V}$ intake was considered a behavior influenced by other risk behaviors, such as tobacco smoking (Neumark-Sztainer et al. 2002).

To the best of the authors' knowledge, there are some studies on the prevalence of $F \& V$ consumption among adolescents in Iran, but they have used different methodologies, questionnaires, cutoff points and objectives than F\&V consumption. Therefore, there is a lack of studies that use a reliable and valid WHO questionnaire about dietary habits among a representative sample of adolescents.

The aim of the present study was to assess the prevalence and correlates of $\mathrm{F} \& \mathrm{~V}$ intake among a representative sample of high school students in the city of Tabriz by using the reliable and valid Persian version of the Global School-based Student Health Survey (GSHS) questionnaire (Ziaei et al. 2014).

\section{Methods}

\section{Study site and sampling}

Iran is a country in the Middle East and, from the WHO perspective, situated in the Eastern Mediterranean Region (EMRO). It has a population of approximately 80 million. The present cross-sectional study was carried out in northwest Iran, in the city of Tabriz, with approximately 2 million inhabitants. Tabriz City, during the 2013-2014 academic years, had 62,714 students at the high school stage (9 to 11th grades) (Scholaro 2018), of which 29,935 were female and 32,779 male.

The sampling method used in this study was two-stage cluster sampling according to the international common protocol of GSHS methodology. At the first stage, high schools were selected with probability proportional to the enrollment size, and at the second stage classes were randomly selected. All students in the selected classes were then eligible to participate in the study. Overall, 30 high schools, including 16 girls' and 14 boys' high schools, and 90 classes (grades 9 to 11) were chosen to participate in the study. The full details of the methodology and Iranian education system have been reported previously (Scholaro 2018; Ziaei et al. 2016; Ziaei et al. 2017). 


\section{Participants}

The whole study population comprised 1517 students, of which 727 were $(47.9 \%)$ male and $790(52.1 \%)$ female. Students' ages ranged from 15 to 17 with a mean of $16.1 \pm$ 0.76 years. From grade 9, 435 (28.7\%) students, from grade $10,539(35.5 \%)$ students, and from grade 11, $543(35.8 \%)$ students participated in the study.

\section{Description of the survey and data collection}

The Global School-based Student Health Survey (GSHS) is a global youth health monitoring surveillance system, providing accurate data on health behaviors among 13-17-year-old students. It is a self-administered, school-based questionnaire in the ten key areas of morbidity and mortality among school adolescents, designed by WHO in collaboration with UNICEF and UNESCO and with technical support from the US Centers for Disease Control and Prevention (CDC) (Global School-based Student Health Survey 2018).

Data for the present study were collected by the reliable, valid and anonymous self-administered "Persian Version of the GSHS" (Ziaei et al. 2014) "Dietary behavior" module (Global School-based Student Health Survey Core Expanded Questionnaire 2009). According to the WHO's GSHS item rationales, the questions in this module measure self-reported height and weight, frequency of hunger, fruit and vegetable consumption, carbonated soft drink consumption and frequency of eating at fast food restaurants (Global School-based Student Health Survey Item Rationale 2009).

Data collection took place from December 2013 to February 2014. Questionnaires were administered to students during an ordinary school day in selected schools and classes by the Province Health Center staff who had attended a workshop on GSHS methodology 1 week prior to the survey date.

\section{Data processing and analysis}

\section{Measures}

There were two dependent outcome variables: fruit intake and vegetable consumption; these were assessed by asking students about the frequency of $\mathrm{F} \& \mathrm{~V}$ intake.

Fruit intake was assessed by the question, "During the past 30 days, how many times per day did you usually eat fruit?" and vegetable intake by the question "During the past 30 days, how many times per day did you eat vegetables?" Both questions had the same response options: I did not eat fruit/ vegetables during the past 30 days; I ate them less than one time per day; one time per day; two times per day; three times per day; four times per day; five or more times per day. Students that reported fruit intake less than two times per day and vegetable consumption less than three times per day were coded as having inadequate consumption.

Hunger was assessed by the question, "During the past 30 days, how often did you go hungry because there was not enough food in your home?" The answers were: never, rarely, sometimes, most of the time and always, with "never," "rarely" and "sometimes" coded " 0 " and "most of the time" and "always" coded as " 1 " in the analysis.

\section{Analysis}

Data analysis was carried out using SPSS software version 24.0. Descriptive statistics were used to report the frequency, percentages, mean and standard deviations. The two main outcome variables were self-reported consumption of fruits and of vegetables. A multivariate logistic regression was used to assess the association between relevant independent variables, such as age, gender, grade and being bullied and the dependent outcome variables ( $\mathrm{F} \& \mathrm{~V}$ consumption, yes/no). Reporting of adjusted odds ratios (AORs) and unadjusted odds ratios (UAORs) was done after controlling for factors identified as significant in the bivariate analysis. AORs and UAORs with 95\% confidence intervals (CI) were reported. $p<0.05$ was considered statistically significant for other statistical tests.

\section{Results}

\section{Prevalence}

Among the studied sample, the prevalence of fruit intake was $76.1 \%$ ( $\geq 2$ times/day) and vegetable intake $23 \%$ ( $\geq 3$ times/ day). Table 1 shows the detailed prevalence of all factors.

\section{Association with fruit intake}

Multivariate regression analysis showed that being at the third level of high school (11 th grade) $[\mathrm{AOR}=1.90 ; 95 \% \mathrm{CI}(1.21-$ 2.99)], sedentary behavior (sitting $\geq 3 \mathrm{~h} /$ day) $[\mathrm{AOR}=1.93$; 95\% CI (1.43-2.61)], low intake of vegetables (intake $<3$ daily) $[\mathrm{AOR}=3.40 ; 95 \% \mathrm{CI}(2.33-4.97)]$, low or lack of parental support $[\mathrm{AOR}=1.52 ; 95 \% \mathrm{CI}(1.17-1.98)]$, low or lack of peer support $[\mathrm{AOR}=1.33 ; 95 \% \mathrm{CI}(1.03-1.73)]$ and the lack of enough food (hunger) in the home $[\mathrm{AOR}=1.47$; 95\% CI (1.03-2.11)] were significantly associated with low consumption of fruit among students (Table 2).

\section{Association with vegetable intake}

Regression analysis showed that being overweight or obese $[\mathrm{AOR}=1.89 ; 95 \% \mathrm{CI}(1.21-2.95)]$, low intake of fruit (intake $<2$ daily) $[\mathrm{AOR}=4.95 ; 95 \% \mathrm{CI}(3.12-7.85)]$, little or lack of peer support $[\mathrm{AOR}=1.36$; 95\% CI (1.03-1.78) $]$ and being 
Table 1 Characteristics of the study participants $(n=1517)$

\begin{tabular}{|c|c|c|c|}
\hline Item & Males no. $(\%)$ & Females no. $(\%)$ & Total no. $(\%)$ \\
\hline \multicolumn{4}{|c|}{ During the past 30 days, how often did you go hungry because there was not enough food in your home? } \\
\hline Never & $432(59.4)$ & $570(72.2)$ & $1002(66.1)$ \\
\hline Rarely & 199 (27.4) & $136(17.2)$ & $335(22.1)$ \\
\hline Sometimes & 84(11.6) & $73(9.2)$ & $157(10.3)$ \\
\hline Most of the time & $9(1.2)$ & $9(1.1)$ & $18(1.2)$ \\
\hline Always & $3(0.4)$ & $2(0.3)$ & $5(0.3)$ \\
\hline \multicolumn{4}{|l|}{ During the past 30 days, how many times per day did you eat fruit? } \\
\hline I did not eat fruit during the past 30 days & $0(0.0)$ & $4(0.5)$ & $4(0.3)$ \\
\hline Less than one time per day & $76(10.5)$ & $54(6.8)$ & $130(8.6)$ \\
\hline 1 time per day & $129(17.7)$ & $100(12.7)$ & $229(15.1)$ \\
\hline 2 times per day & $164(22.6)$ & $167(21.1)$ & $331(21.8)$ \\
\hline 3 times per day & $190(26.1)$ & $232(29.4)$ & $422(27.8)$ \\
\hline 4 times per day & 85 (11.7) & $118(14.9)$ & $203(13.4)$ \\
\hline 5 or more times per day & $83(11.4)$ & $115(14.6)$ & $198(13.1)$ \\
\hline \multicolumn{4}{|c|}{ During the past 30 days, how many times per day did you eat vegetables? } \\
\hline I did not eat vegetables during the past 30 days & $71(9.8)$ & $44(5.6)$ & $115(7.6)$ \\
\hline Less than one time per day & $178(24.5)$ & $238(30.1)$ & $416(27.4)$ \\
\hline 1 time per day & $176(24.2)$ & $183(23.2)$ & $359(23.7)$ \\
\hline 2 times per day & $138(19.0)$ & 140 (17.7) & $278(18.3)$ \\
\hline 3 times per day & 84 (11.6) & $118(14.9)$ & $202(13.3)$ \\
\hline 4 times per day & $26(3.6)$ & $36(4.6)$ & $62(4.1)$ \\
\hline 5 or more times per day & $54(7.4)$ & $31(3.9)$ & $85(5.6)$ \\
\hline \multicolumn{4}{|c|}{ During the past 30 days, how many times per day did you drink carbonated soft drinks? } \\
\hline I did not drink carbonated soft drinks during the past 30 days & $154(21.2)$ & $135(17.1)$ & $289(19.1)$ \\
\hline Less than 1 time per day & $288(39.6)$ & $278(35.2)$ & $566(37.3)$ \\
\hline 1 time per day & $106(14.6)$ & $148(18.7)$ & $254(16.7)$ \\
\hline 2 times per day & $71(9.8)$ & $106(13.4)$ & $177(11.7)$ \\
\hline 3 times per day & $30(4.1)$ & $65(8.2)$ & $95(6.3)$ \\
\hline 4 times per day & $32(4.4)$ & $21(2.7)$ & $53(3.5)$ \\
\hline 5 or more times per day & $46(6.3)$ & $37(4.7)$ & $83(5.5)$ \\
\hline \multicolumn{4}{|c|}{ During the past 7 days, on how many days did you eat food from a fast food restaurant? } \\
\hline 0 days & $275(37.8)$ & $187(23.7)$ & $462(30.5)$ \\
\hline 1 day & $184(25.3)$ & $251(31.8)$ & $435(28.7)$ \\
\hline 2 days & $133(18.3)$ & $156(19.7)$ & $289(19.1)$ \\
\hline 3 days & $78(10.7)$ & $111(14.1)$ & $189(12.5)$ \\
\hline 4 days & $16(2.2)$ & $45(5.7)$ & $61(4.0)$ \\
\hline 5 days & $16(2.2)$ & $16(2.0)$ & $32(2.1)$ \\
\hline 6 days & $19(2.6)$ & $17(2.2)$ & $36(2.4)$ \\
\hline 7 days & $6(0.8)$ & $7(0.9)$ & $13(0.9)$ \\
\hline
\end{tabular}

physically inactive $(<5$ day/week) $[\mathrm{AOR}=1.45 ; 95 \% \mathrm{CI}$ $(1.08-1.95)]$ were significantly associated with low intake of vegetables (Table 3 ).

\section{Discussion}

The present study examined the prevalence and correlates of adequate $\mathrm{F} \& \mathrm{~V}$ intake among high school students in the city of Tabriz by using the GSHS questionnaire based on the frequency of intake per day and not the portion sizes. According to the self-reported fruit intake, $76.1 \%$ of students consumed $\geq 2$ time/day and $23.9 \%$ consumed $<2$ times per day, which, according to the US Department of Health and Human Services (Healthypeople 2018) cutoff points, meant that most of the students $(76.1 \%)$ met the recommended fruit intake. In contrast, for vegetable intake, only $23 \%$ of the students reported an adequate level and $77 \%$ consumed less than the daily recommended intake $(\geq$ 3 times/day). In some research, the cutoff points for adequate fruit intake are defined as $\geq 5$ or $\geq 7$ times/day, which compared with our results show a huge difference. According to the literature (State Indicator Report on Fruits and Vegetables 2013; Agudo 2004; Adults Meeting Fruit and Vegetable Intake Recommendations 2013), most countries have their own definitions of the adequate cutoff points, but by providing the information in Table 1, our results can be easily compared with other studies and different cutoff points. In a GSHS study in seven African countries (Peltzer and Pengpid 2010) among high school students, the adequate cutoff point was $\geq 5$ times/daily, where $77.5 \%$ consumed $<5$ times/day and $36 \%$ of the boys and $32.6 \%$ of the girls had inadequate fruit and vegetable consumption (less than once per day), respectively. In another GSHS study in 11 EMRO countries (Al Ani et al. 2016), among high school students, overall $19.4 \%$ of the students consumed $\mathrm{F} \& \mathrm{~V} \geq 5$ times/day. In the US, just $22.3 \%$ of adolescents had adequate intake of $\mathrm{F} \& \mathrm{~V}$ per day (Eaton et al. 2010). Variations in assessment approaches and cutoff points should be accounted for when comparing results. 
Table 2 Associations between fruit intake and independent variables among students $(n=1517)$

\begin{tabular}{|c|c|c|}
\hline $\begin{array}{l}\text { Independent } \\
\text { variables }\end{array}$ & UAOR CI 95\% & AOR CI $95 \%$ \\
\hline
\end{tabular}

Age $^{\mathrm{a}}$ in years

$\begin{array}{lllll}15 & 1.00 & & & \\ 16 & 1.68 & 1.18-2.41^{* *} & 1.20 & 0.80-1.79 \\ 17 & 1.89 & 1.30-2.74 * * & 0.95 & 0.55-1.63 \\ \begin{array}{l}\text { Gender } \\ \text { Girl }\end{array} & & & & \\ \text { Boy }^{\mathrm{b}} & 0.63 & 0.50-0.80^{* * * * *} & 0.84 & 0.63-1.11 \\ \text { Grade }^{\mathrm{a}} & 1.00 & & & \\ \text { First }^{\mathrm{eb}} & & & & \\ \text { Second }^{\mathrm{c}} & 1.00 & & & \\ \text { Third }^{\mathrm{d}} & 1.59 & 1.16-2.19 * * & 1.32 & 0.91-1.90 \\ & 1.96 & 1.44-2.68 * * * * & 1.90 & 1.21-2.99 * *\end{array}$

Sedentary behavior ( $\geq 3 \mathrm{~h} /$ days)

\begin{tabular}{lcccc} 
Yes & 1.97 & $1.47-2.63^{* * * *}$ & 1.93 & $1.43-2.61^{* * * *}$ \\
No & 1.00 & & & \\
Vegetables intake $\geq 3$ daily) & & & \\
Yes & 1.00 & & & \\
No & 3.50 & $2.41-5.08^{* * * *}$ & 3.40 & $2.33-4.97^{* * * *}$ \\
Parental support & & & & \\
Yes & 1.00 & & & \\
No & 1.71 & $1.34-2.18^{* * * * *} 1.52$ & $1.17-1.98^{* *}$ \\
Parental connectivity & & & & \\
Yes & 1.00 & & & \\
No & 1.32 & $1.08-1.68^{*}$ & 1.08 & $0.83-1.41$ \\
Peer support & & & & \\
Yes & 1.00 & & & \\
No & 1.59 & $1.24-2.03^{* * * * *} 1.33$ & $1.03-1.73^{*}$ \\
Fizzy drinks & & & & \\
Yes & 0.91 & $0.56-1.01$ & & \\
No & 1.00 & & & \\
Fast foods & & & & \\
Yes & 0.92 & $0.72-1.17$ & & \\
No & 1.00 & & & \\
Hunger & & & & \\
Yes & 1.47 & $1.04-2.06^{*}$ & 1.47 & $1.03-2.11^{*}$ \\
No & 1.00 & & & \\
\hline
\end{tabular}

$C I$ confidence interval, UAOR unadjusted odds ratio, $A O R$ adjusted odds ratio,

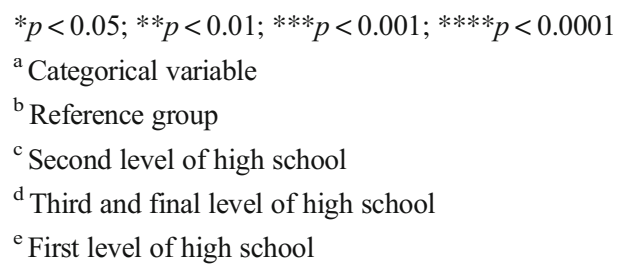

According to our results, the students in the final year of high school (11th grade) had 90\% higher odds of consuming less fruit than in the second grade of high school. This means that, with increasing high school grade and age, the tendency for fruit intake decreases. Studies in 11 EMRO countries (Al Ani et al. 2016) and the USA (Larson et al. 2007) and Australia (Mikkila et al. 2005) also reported the same results. This negative association may persist from adolescence into adulthood (Mikkila et al. 2005; NeumarkSztainer et al. 2002). Students with sedentary behavior (sitting $\geq 3 \mathrm{~h} /$ day) had $93 \%$ higher odds of eating less fruit than students sitting $<3 \mathrm{~h}$ per day. According to an Iranian study (Caspian III), screen-time activities, such as watching TV, playing games, mobile surfing or working with a computer, comprises $>4 \mathrm{~h}$ per day among Iranian adolescents, of which at least $3 \mathrm{~h}$ is watching TV (Baygi et al. 2015). Therefore, sedentary behavior leads to the intake of unhealthy food choices such as salty, fatty and junk foods and, in contrast, less F\&V intake (Kelishadi et al. 2007). The students that reported not having adequate vegetable intake ( $\geq 3$ times/ day) had 3.40 times higher odds of inadequate fruit intake; students not having adequate fruit intake ( $\geq 2$ times/daily) also had 4.95 times higher odds of inadequate vegetable intake. The students that were overweight or obese had $89 \%$ higher odds of eating fewer vegetables. According to the study, boys and girls who were significantly overweight consumed less F\&V than those of normal weight (Nystrom et al. 2005). In the present study, higher BMI was not associated with fruit intake. In some studies (Hart et al. 2010), higher intake of F\&V was supposed to decrease BMI and help weight management among adolescents, but the study of an association between F\&V intake and BMI change did not show a positive effect (Field et al. 2003).

Parental and peer supports are two important factors that affect adolescents' $F \& V$ intake and healthy eating habits. According to the systematic review (Pearson et al. 2009), parental intake, education and support were positively associated with children's F\&V intake. Our study showed the same results; students without parental support had 52\% higher odds of consuming less fruit than students that reported parental support: peer support also plays an important role, and students without peer support had 33\% higher odds of consuming less fruit. Students without peer support also had 36\% higher odds of eating fewer vegetables.

Students that reported hunger had $47 \%$ higher odds of consuming less fruit than the students that did not report hunger. Food security, as well as availability of food or F\&V, is another issue that needs more research and attention.

Furthermore, we found that physically inactive students had $45 \%$ higher odds of consuming fewer vegetables than active students. A recent study from Brazil has also shown that adolescents who were insufficiently active had a $50 \%$ higher chance of consuming fewer vegetables than those who were active (Silva and Silva 2015). This suggests that inactive students have other unhealthy eating behaviors that can increase their risk for NCDs. 
Table 3 Associations between vegetable intake and independent variables among students $(n=$ 1517)

\begin{tabular}{|c|c|c|c|c|}
\hline Independent variables & UAOR & CI $95 \%$ & AOR & CI $95 \%$ \\
\hline \multicolumn{5}{|l|}{ Age $^{\mathrm{a}}$ in years } \\
\hline 15 & 1.00 & & & \\
\hline 16 & 1.18 & $0.93-1.75$ & 1.10 & $0.76-1.61$ \\
\hline 17 & 1.47 & $1.05-2.07 *$ & 1.03 & $0.60-1.77$ \\
\hline \multicolumn{5}{|l|}{ Gender $^{\mathrm{a}}$} \\
\hline Girl & 0.95 & $0.75-1.21$ & & \\
\hline Boy $^{b}$ & 1.00 & & & \\
\hline \multicolumn{5}{|l|}{ Grade $^{\text {a }}$} \\
\hline First $^{\mathrm{eb}}$ & 1.00 & & & \\
\hline Second ${ }^{c}$ & 1.09 & $0.81-1.46$ & 0.86 & $0.61-1.22$ \\
\hline Third $^{\mathrm{d}}$ & 1.46 & $1.08-1.98 *$ & 1.31 & $0.79-2.15$ \\
\hline \multicolumn{5}{|c|}{ Sedentary behavior ( $\geq 3 \mathrm{~h} /$ days $)$} \\
\hline Yes & 1.05 & $0.81-1.37$ & & \\
\hline No & 1.00 & & & \\
\hline \multicolumn{5}{|l|}{$\mathrm{BMI}^{\mathrm{a}}$} \\
\hline Normal/underweight ${ }^{\mathrm{b}}$ & 1.00 & & & \\
\hline Overweight/obese & 1.76 & $1.14-2.71 *$ & 1.89 & $1.21-2.95 * *$ \\
\hline \multicolumn{5}{|l|}{ Fruit intake ( $\geq 2$ daily) } \\
\hline Yes & 1.00 & & & \\
\hline No & 3.50 & $2.41-5.08 * * * *$ & 4.95 & $3.12-7.85 * * * *$ \\
\hline \multicolumn{5}{|l|}{ Parental support } \\
\hline Yes & 1.00 & & & \\
\hline No & 1.20 & $0.93-1.55$ & & \\
\hline \multicolumn{5}{|l|}{ Parental connectivity } \\
\hline Yes & 1.00 & & & \\
\hline No & 1.15 & $0.90-1.46$ & & \\
\hline \multicolumn{5}{|l|}{ Peer support } \\
\hline Yes & 1.00 & & & \\
\hline No & 1.31 & $1.03-1.66^{*}$ & 1.36 & $1.03-1.78^{*}$ \\
\hline \multicolumn{5}{|l|}{ Fizzy drinks } \\
\hline Yes & 1.01 & $0.74-1.37$ & & \\
\hline No & 1.00 & & & \\
\hline \multicolumn{5}{|l|}{ Fast foods } \\
\hline Yes & 0.93 & $0.73-1.19$ & & \\
\hline No & 1.00 & & & \\
\hline \multicolumn{5}{|l|}{ Hunger } \\
\hline Yes & 0.85 & $0.59-1.22$ & & \\
\hline No & 1.00 & & & \\
\hline \multicolumn{5}{|c|}{ Physical activity ( $\geq 5$ days/week) } \\
\hline Yes & 1.00 & 1.00 & & \\
\hline No & 1.56 & $1.20-2.01 * *$ & 1.45 & $1.08-1.95^{*}$ \\
\hline
\end{tabular}

CI confidence interval, UAOR unadjusted odds ratio, $A O R$ adjusted odds ratio

${ }^{*} p<0.05 ; * * p<0.01 ; * * * p<0.001 ; * * * * p<0.0001$

${ }^{\text {a }}$ Categorical variable

${ }^{\mathrm{b}}$ Reference group

${ }^{\mathrm{c}}$ Second level of high school

${ }^{\mathrm{d}}$ Third and final level of high school

${ }^{\mathrm{e}}$ First level of high school

\section{Study limitations}

This study used the WHO GSHS self-reported questionnaire for data collection, so results are valid only for adolescents who are attending school and may not be representative of those not at school. Despite the anonymous nature of the survey, missed, over- or underreporting may have taken place. The correlates of F\&V intake were limited to the questionnaire. Many other important factors, such as family intake, education, income, home availability and accessibility of fruit, school nutrition education, social situation, etc., should be included in future and more comprehensive studies. The present study was a cross-sectional study and did not allow establishing causality to any of the associated factors in the study.

\section{Conclusion}

The level of fruit intake was high according to our cutoff points among students, but not vegetable intake. Interventions targeting sedentary behavior, low intake of vegetables and fruit, lack of parental support, lack of peer support and hunger can be given more priority by concerned authorities. 
Acknowledgements The authors thank the study participants for their contribution to the study, as well as the study investigators and staff. This research was possible because of collaboration among the Tabriz Province Health Center, Province Ministry of Education and Tabriz University of Medical Sciences. Special thanks to Mr. Vahab Asl Rahimi, Mr. Abolfazl Jeddi and Mrs. Mino Mahini from the Tabriz Province Health Center and Mr. Hamid Mehmandoost from the Province Ministry of Education.

Funding This work was supported by the Research Committee of Tabriz University of Medical Sciences, grant no. 5/4/8860.

\section{Compliance with ethical standards}

Conflict of interest The authors declare that they have no conflict of interest.

Informed consent Informed consent was obtained from all individual participants included in the study.

Ethical considerations The Ethics Committee of Tabriz University of Medical Sciences granted approval for the study [5/4/7180, 1391/08/10]. One week prior to the survey, consent forms were distributed to all parents of students in the participating classes through the school authorities and these were collected from students on the day of administration. All students were informed about the voluntary and anonymous nature of the study and were told that they could terminate their participation at any time during the survey.

All procedures performed in studies involving human participants were in accordance with the ethical standards of the institutional and/or national research committee and with the 1964 Helsinki Declaration and its later amendments or comparable ethical standards.

Open Access This article is distributed under the terms of the Creative Commons Attribution 4.0 International License (http:// creativecommons.org/licenses/by/4.0/), which permits unrestricted use, distribution, and reproduction in any medium, provided you give appropriate credit to the original author(s) and the source, provide a link to the Creative Commons license, and indicate if changes were made.

\section{References}

Adults Meeting Fruit and Vegetable Intake Recommendations United States (2013) https://www.cdc.gov/mmwr/preview/mmwrhtml/ mm6426a1.htm. Accessed 30 May 2017

Agudo A (2004) Joint FAO/WHO Workshop on Fruit and Vegetables for Health. Kobe J (2018) Measuring intake of fruit and vegetables. http://apps.who.int/iris/handle/10665/43144. Accessed 7 Nov 2018

Al Ani MF, Al Subhi LK, Bose S (2016) Consumption of fruits and vegetables among adolescents: a multi-national comparison of eleven countries in the eastern Mediterranean region. Br J Nutr 115: 1092-1099. https://doi.org/10.1017/s0007114515005371

Baygi F, Heshmat R, Kelishadi R, Mohammadi F, Motlagh ME, Ardalan G, Asayesh H, Larijani B, Qorbani M (2015) Regional disparities in sedentary behaviors and meal frequency in Iranian adolescents: the CASPIAN-III study. Iran J Pediatr 25:e182. https://doi.org/10.5812/ijp.182

Doku D, Koivusilta L, Raisamo S, Rimpela A (2013) Socio-economic differences in adolescents' breakfast eating, fruit and vegetable consumption and physical activity in Ghana. Public Health Nutr 16: 864-872. https://doi.org/10.1017/s136898001100276x
Eaton DK, Kann L, Kinchen S, Shanklin S, Ross J, Hawkins J, Harris WA, Lowry R, McManus T, Chyen D, Lim C, Whittle L, Brener ND, Wechsler H (2010) Youth risk behavior surveillance-United States, 2009. Morb Mortal Wkly Rep Surveill Summ 59:1-142

Field AE, Gillman MW, Rosner B, Rockett HR, Colditz GA (2003) Association between fruit and vegetable intake and change in body mass index among a large sample of children and adolescents in the United States. Int J Obes Relat Metab Disord 27:821-826. https:// doi.org/10.1038/sj.ijo.0802297

Global school-based student health survey (2018) World Health Organization. http://www.who.int/chp/gshs/en/. Accessed 7 November 2018

Global school-based student health survey core expanded questionnaire (2009) http://www.who.int/chp/gshs/GSHS_Questionnaire_Core Expanded_2009_English.pdf?ua=1. Accessed 30 May 2017

Global school-based student health survey Item Rationale (2009) http:// www.who.int/chp/gshs/GSHS_Item_Rationales_2009_English. pdf?ua=1. Accessed 30 May 2017

Hart CN, Jelalian E, Raynor HA, Mehlenbeck R, Lloyd-Richardson EE, Kaplan J, Flynn-O'Brien K, Wing RR (2010) Early patterns of food intake in an adolescent weight loss trial as predictors of BMI change. Eat Behav 11:217-222. https://doi.org/10.1016/j. eatbeh.2010.05.001

Health gov (2018) 2015-2020 dietary guidelines - health.gov. https:// health.gov/dietaryguidelines/2015/guidelines/. Accessed 7 Nov 2018

Healthypeople (2018) Healthy People 2010 Home Page. https:/www. healthypeople.gov/2010/. Accessed 30 May 2017

Kelishadi R, Ardalan G, Gheiratmand R, Gouya MM, Razaghi EM, Delavari A, Majdzadeh R, Heshmat R, Motaghian M, Barekati H, Mahmoud-Arabi MS, Riazi MM (2007) Association of physical activity and dietary behaviours in relation to the body mass index in a national sample of Iranian children and adolescents: CASPIAN Study. Bull World Health Organ 85:19-26

Key TJ, Allen NE, Spencer EA, Travis RC (2002) The effect of diet on risk of cancer. Lancet 360:861-868. https://doi.org/10.1016/s01406736(02)09958-0

Kimmons J, Gillespie C, Seymour J, Serdula M, Blanck HM (2009) Fruit and vegetable intake among adolescents and adults in the United States: percentage meeting individualized recommendations. Medscape J Med 11:26

Larson NI, Neumark-Sztainer D, Hannan PJ, Story M (2007) Trends in adolescent fruit and vegetable consumption, 1999-2004: project EAT. Am J Prev Med 32:147-150. https://doi.org/10.1016/j. amepre.2006.10.011

Lynch C, Kristjansdottir AG, Te Velde SJ, Lien N, Roos E, Thorsdottir I, Krawinkel M, de Almeida MD, Papadaki A, Hlastan Ribic C, Petrova S, Ehrenblad B, Halldorsson T, Poortvliet E, Yngve A (2014) Fruit and vegetable consumption in a sample of 11-yearold children in ten European countries - the PRO GREENS crosssectional survey. Public Health Nutr 17:2436-2444. https://doi.org/ $10.1017 / \mathrm{s} 1368980014001347$

Mikkila V, Rasanen L, Raitakari OT, Pietinen P, Viikari J (2005) Consistent dietary patterns identified from childhood to adulthood: the cardiovascular risk in young Finns study. Br J Nutr 93:923-931

Neumark-Sztainer D, Story M, Hannan PJ, Croll J (2002) Overweight status and eating patterns among adolescents: where do youths stand in comparison with the healthy people 2010 objectives? Am J Public Health 92:844-851

Nystrom AA, Schmitz KH, Perry CL, Lytle LA, Neumark-Sztainer D (2005) The relationship of weight related perceptions, goals, and behaviors with fruit and vegetable consumption in young adolescents. Prev Med 40:203-208. https://doi.org/10.1016/j.ypmed.2004.05.022

Paudel S, Subedi N, Bhandari R, Bastola R, Niroula R, Poudyal AK (2014) Estimation of leisure time physical activity and sedentary 
behaviour among school adolescents in Nepal. BMC Public Health 14:637. https://doi.org/10.1186/1471-2458-14-637

Pearson N, Biddle SJ, Gorely T (2009) Family correlates of fruit and vegetable consumption in children and adolescents: a systematic review. Public Health Nutr 12:267-283. https://doi.org/10.1017/ s1368980008002589

Peltzer K, Pengpid S (2010) Fruits and vegetables consumption and associated factors among in-school adolescents in seven African countries. Int J Public Health 55:669-678. https://doi.org/10.1007/ s00038-010-0194-8

Rasmussen M, Krolner R, Klepp KI, Lytle L, Brug J, Bere E, Due P (2006) Determinants of fruit and vegetable consumption among children and adolescents: a review of the literature. Part I: quantitative studies. Int J Behav Nutr Phys Act 3:22. https://doi.org/10.1186/ $1479-5868-3-22$

Scholaro (2018) Iran Education System. https://www.scholaro.com/pro/ Countries/Iran/Education-System. Accessed 7 Nov 2018

Shokrvash B, Majlessi F, Montazeri A, Nedjat S, Shojaeezadeh D, Rahimi A, Djazayeri A, Saghafi Asl M (2013) Fruit and vegetables consumption among adolescents: a study from a developing country. https://pdfs.semanticscholar.org/dfa2/ f29e0a488661fd851c80c573f4bf042b2d08.pdf. Accessed 7 Nov 2018

Silva DA, Silva RJ (2015) Association between physical activity level and consumption of fruit and vegetables among adolescents in Northeast Brazil. Rev Paul Pediatr 33:167-173. https://doi.org/10. 1016/j.rpped.2014.09.003

State Indicator Report on Fruits and Vegetables (2013) https://www.cdc. gov/nutrition/downloads/state-indicator-report-fruits-vegetables2013.pdf. Accessed 30 May 2017. Accessed 7 Nov 2018

UN Secretary-General Report (2011) Prevention and control of non-communicable diseases. http://www.who.int/nmh/events/un_ncd summit2011/political_declaration_en.pdf. Accessed 7 Nov 2018

Veltsista A, Kanaka C, Gika A, Lekea V, Roma E, Bakoula C (2010) Tracking of overweight and obesity in Greek youth. Obes Facts 3: 166-172. https://doi.org/10.1159/000314620

Vereecken C, Kristiina O, Jordan M (2004) Young people's health in context. Health behaviour in school-aged children (HBSC) study: international report from the 2001/2002 survey. World Health Organization WHO Regional Office for Europe, Copenhagen, $\mathrm{p}$
110-119. http://www.who.int/immunization/hpv/target/young peoples_health_in_context_who_2011_2012.pdf. Accessed 7 Nov 2018

World Health Organization (2003) Fruit and vegetable promotion initiative / A meeting report / 25-27/08/03. http://www.who.int/ dietphysicalactivity/publications/f\&v_promotion_initiative_report. pdf?ua $=1$. Accessed 7 Nov 2018

World Health Organization (2018) Preventing chronic diseases: a vital investment. http://www.who.int/chp/chronic_disease report/en/. Accessed 7 Nov 2018

Yngve A, Wolf A, Poortvliet E, Elmadfa I, Brug J, Ehrenblad B, Franchini B, Haraldsdóttir J, Krølner R, Maes L, Pérez-Rodrigo C, Sjostrom M, Thórsdóttir I, Klepp KI (2005) Fruit and vegetable intake in a sample of 11-year-old children in 9 European countries: the pro children cross-sectional survey. Ann Nutr Metab 49:236245. https://doi.org/10.1159/000087247

Zhang CX, Chen YM, Chen WQ, Su YX, Wang CL, Wu JN (2012) Food group intake among adolescents in Guangzhou city compared with the Chinese dietary guidelines. Asia Pac J Clin Nutr 21:450-456

Ziaei R, Dastgiri S, Soares J, Baybordi E, Zeinalzadeh A, Asl Rahimi V, Mohammadi R (2014) Reliability and validity of the Persian version of global school-based student health survey adapted for Iranian school students. J Clin Res Gov 2014(3):7. https://doi.org/10. 13183/jcrg.v3i2.138

Ziaei R, Mohammadi R, Dastgiri S, Viitasara E, Rahimi VA, Jeddi A, Soares J (2016) The prevalence, attitudes, and correlates of water pipe smoking among high school students in Iran: a cross-sectional study. Int J Behav Med. https://doi.org/10.1007/s12529-016-9555-x

Ziaei R et al (2017) Suicidal ideation and its correlates among high school students in Iran: a cross-sectional study. BMC Psychiatry 17:147. https://doi.org/10.1186/s12888-017-1298-y

Publisher's note Springer Nature remains neutral with regard to jurisdictional claims in published maps and institutional affiliations. 